\title{
ESTUDO DA ADSORÇÃO DE CELULASE EM BAGAÇO DE CANA- DE-AÇÚCAR PRÉ-TRATADO DURANTE HIDRÓLISE ENZIMÁTICA
}

\author{
J. MOREIRA NETO ${ }^{1}$, D. L. MACHADO ${ }^{1}$, A. M. F. L. J. BONOMI ${ }^{2}$, S. C. RABELO ${ }^{2}$, J. G. C. \\ PRADELLA ${ }^{2}$ e A. C. da COSTA $^{1}$ \\ ${ }^{1}$ Universidade Estadual de Campinas, Faculdade de Engenharia Química \\ ${ }^{2}$ Laboratório Nacional de Ciência e Tecnologia do Bioetanol (CTBE/CNPEM) \\ E-mail para contato: joaomn_engq@yahoo.com.br
}

\begin{abstract}
RESUMO - A adsorção enzimática pode depender do tipo de substrato utilizado e desde que as características do substrato podem mudar com a conversão, é importante que o modelo leve em consideração a variação na quantidade de celulase adsorvida durante a hidrólise enzimática. Neste trabalho foi avaliada a influência do tempo de hidrólise sobre os parâmetros da isoterma de Langmuir na adsorção da celulase no bagaço de cana-deaçúcar submetido ao pré-tratamento hidrotérmico $(\mathrm{BH})$. $\mathrm{O}$ modelo de Langmuir utilizado para descrever as isotermas de adsorção foi capaz de representar bem os dados experimentais obtidos para o sistema celulose-celulase. O estudo da adsorção da celulase em amostras de $\mathrm{BH}$ coletadas em diferentes tempos de hidrólise mostrou que a adsorção máxima da enzima $\left(\mathrm{E}_{\max }\right)$ no substrato diminui com o decorrer da reação.
\end{abstract}

\section{INTRODUÇÃO}

A hidrólise enzimática de biomassas lignocelulósicas em açúcares solúveis para produção de bioetanol tem sido extensivamente estudada. Entretanto, ainda existem obstáculos para o processo em larga escala, onde a taxa de hidrólise diminui rapidamente ao longo do tempo, resultando em tempos de processo longos para alcançar a conversão da celulose desejada. Para superar isto, grandes quantidades de enzimas são necessárias, o que resulta em altos custos de processo (Börjesson et al., 2007I; Levine et al., 2010 ).

O mecanismo de hidrólise enzimática da celulose ainda não é bem compreendido. A complexidade do sistema, que surge a partir da ação conjunta de várias enzimas que atuam sobre o substrato sólido heterogêneo, torna os experimentos cinéticos e estudos mecanísticos difíceis e como resultado, as características determinantes do sistema celulase-celulose têm ainda de serem identificadas (Levine et al., 2010).

Embora a adsorção da celulase em substratos sólidos seja a primeira etapa da hidrólise enzimática da celulose em açúcares solúveis e as taxas de hidrólise e/ou rendimentos estarem 


\section{9 a 22 de outubro de 2014 \\ Florianópolis/SC}

diretamente relacionadas à quantidade de enzima adsorvida (Kumar e Wyman, 2009), pouca informação é disponível nas interações substrato-enzima, incluindo cinética de adsorção da celulase e acessibilidade da enzima por lignina e celulose em biomassas pré-tratadas. Isotermas de adsorção são amplamente utilizadas por diversos pesquisadores (Zhang e Lynd, 2004; Kadam et al, 2004; Zheng et al. 2013) para a quantificação da celulase adsorvida sobre as superfícies de materiais lignocelulósicos pré-tratados e/ou Avicel. Os resultados apresentados por Xue et al.(2012) sugerem que é benéfico a dosagem de enzimas de acordo com as características de adsorção do sistema, a fim de desenvolver um melhor processo para aplicações industriais.

Os estudos que investigaram mudanças na adsorção individual de enzimas foram conduzidos antes e após a hidrólise, e não durante a hidrólise (Tu el al., 2007; Sipos et al., 2010). Dessa forma seria desejável obter informação mais detalhada dos perfis de adsorção das enzimas presentes em coquetéis enzimáticos de celulase durante a hidrólise, uma vez que podem ocorrer modificações nas características dos substratos lignocelulósicos ao longo da reação.

O objetivo deste trabalho foi avaliar o comportamento da adsorção da celulase em bagaço de cana-de-açúcar submetido ao pré-tratamento hidrotérmico durante a hidrólise enzimática. Com este propósito foram determinadas isotermas de adsorção a partir de amostras de bagaço pré-tratado coletadas em diferentes tempos de hidrólise.

\section{MATERIAIS E MÉTODOS}

\subsection{Substrato e pré-tratamento}

O substrato utilizado em todos os experimentos foi o bagaço de cana-de-açúcar (Saccharum officinarum) submetido ao pré-tratamento hidrotérmico. O bagaço foi proveniente de uma mesma safra (2011/12) e fornecido pela Usina Tarumã do Grupo Raízen, localizada na cidade de Tarumã, Estado de São Paulo, obtido por colheita mecanizada da cana-de-açúcar e resultante da última moenda após a extração do caldo. O bagaço de cana-de-açúcar foi seco a temperatura ambiente por quatro dias, moído em moinho de corte (Pulverisette 19, Fritsch) sendo posteriormente peneirado com uma peneira de $0,5 \mathrm{~mm}$. $\mathrm{O}$ bagaço de cana previamente moído foi pré-tratado a $190^{\circ} \mathrm{C}$ por 10 mim em reator liga C276 (Parr, modelo 4532). $300 \mathrm{~g}$ do bagaço foram adicionados ao reator com $3 \mathrm{~L}$ água destilada mantendo a relação sólido-líquido de 1:10 (m/v). Após pré-tratamento, o bagaço hidrotérmico $(\mathrm{BH})$ foi lavado para remoção de compostos solúveis presentes no hidrolisado, seco a temperatura ambiente e armazenado em sacos plásticos fechados.

\subsection{Atividade enzimática}

Atividade celulolítica foi determinada como unidades de papel de filtro por mililitro (FPU/mL), conforme recomendado pela União Internacional de Química Pura e Aplicada (Ghose (1987) e Adney e Baker (1996)). Atividade da $\beta$-glicosidase foi determinada utilizando uma solução de celobiose 15 $\mathrm{mmol} / \mathrm{L}$ e expressa em unidades por mililitro (CBU/mL) (Wood e Bhat, (1988)). A atividade enzimática foi de $87,74 \mathrm{FPU} / \mathrm{ml}$ para celulase e $617,33 \mathrm{CBU} / \mathrm{mL}$ para $\beta$-glicosidase. 


\section{9 a 22 de outubro de 2014 \\ Florianópolis/SC}

\subsection{Hidrólise enzimática e ensaios de dessorção}

A hidrólise enzimática do bagaço pré-tratado foi realizada em erlenmeyers de $500 \mathrm{~mL}$, contendo uma mistura de $200 \mathrm{~mL}$ de tampão citrato $0,05 \mathrm{M}(\mathrm{pH} 4,8)$ complementado com $0,02 \%$ azida sódica por grama de biomassa e $10 \%(\mathrm{~m} / \mathrm{v})$ de bagaço hidrotérmico $(\mathrm{BH})$. A carga enzimática de celulase (celulase de Trichoderma reesei, Celluclast $1.5 \mathrm{~L}$ da Novozyme) e $\beta$-glicosidase (Aspergillus niger, Novozym 188) foram de $15 \mathrm{FPU} / \mathrm{g}$ de $\mathrm{BH}$ e $25 \mathrm{CBU} / \mathrm{g}$ de $\mathrm{BH}$, respectivamente. Os frascos foram incubados em agitador orbital (Marconi MA-832), agitado a $150 \mathrm{rpm}$ a $50{ }^{\circ} \mathrm{C}$ e as enzimas só foram adicionadas após uma hora de incubação. Cada frasco foi retirado num tempo de reação diferente (1, 6, 12 e 18 horas) onde o resíduo de hidrólise foi separado do hidrolisado e lavado com água.

A dessorção da enzima ligada ao substrato residual obtido em cada tempo de hidrólise foi conduzida de acordo com as condições descritas por Pribowo et al.(2012), onde após a lavagem com água, aos resíduos foram adicionados em $100 \mathrm{~mL}$ de uma solução contendo tampão acetato 0,05 M $(\mathrm{pH} 5,3)$ com $0,5 \%$ de tween $80(\mathrm{v} / \mathrm{v})$, seguindo para incubadora por $2 \mathrm{~h}$ a $44^{\circ} \mathrm{C}$. Após esse período, as suspenções foram sonicadas a $40 \mathrm{KHz}$ por 60 minutos no aparelho UltraSonic clear USC-2800 (Unique, Brasil). Em seguida, os substratos foram lavados por mais 3 vezes com água destilada e secos em temperatura ambiente.

\subsection{Isoterma de adsorção da celulase}

A isoterma de adsorção da celulase foi realizada variando-se a quantidade de proteína $(0,1-4,5$ $\mathrm{mg} / \mathrm{mL})$ adicionada numa concentração fixa de substrato de $5 \%(\mathrm{~m} / \mathrm{v})$. Foram feitas isotermas para o $\mathrm{BH}$ e para os substratos resultantes da hidrólise enzimática do $\mathrm{BH}$ nos tempos de 1, 6, 12 e $18 \mathrm{~h}$, respectivamente (ver seção 2.3). Os ensaios foram feitos em duplicata em erlenmeyer de $125 \mathrm{~mL} c \mathrm{~cm}$ volume reacional de $15 \mathrm{~mL}$, onde foram adicionados a biomassa, tampão de citrato de sódio $\mathrm{pH} 4,8$ $50 \mathrm{mM}$ complementado com $0,02 \%$ de azida sódica por grama de biomassa. Para medir o fenômeno de adsorção da celulase independente da hidrólise do substrato pela enzima, uma solução de D-(+)glicose com concentração 100 vezes maior que a concentração protéica da enzima usada nos ensaios foi adicionada ao meio reacional para que a enzima celulase fosse inibida e não houvesse reação conforme demonstrado no trabalho de Maurer et al. (2012). Os frascos foram incubados em agitador orbital (Marconi MA-832), agitado a $150 \mathrm{rpm}$ a $50{ }^{\circ} \mathrm{C}$ por 3 horas para se atingir o equilíbrio. Após o experimento o sobrenadante de cada frasco foi recolhido, centrifugado (NT 810 Novatecnica, Brasil) e filtrado utilizando filtros MILLEX - HV com membrana de PVDF, 0,45 $\mu \mathrm{m}$ de poro, $13 \mathrm{~mm}$ de diâmetro (Milipore).

As amostras foram analisadas para a quantificação do teor de proteínas pelo método de Bradford (1976). O teor de proteína no sobrenadante foi determinado como celulase livre em solução. A celulase adsorvida ao substrato foi calculada pela subtração da proteína livre em solução da proteína adicionada inicialmente.

\section{RESULTADOS E DISCUSSÃO}

Diversos estudos com adsorção de celulases em substatos celulósicos e lignocelulósicos foram 
conduzidos à temperatura de $4^{\circ} \mathrm{C}$, pois nessa temperatura é possível estudar o fenômeno de adsorção sem a presença da hidrólise da celulose (Kumar e Wyman, 2009; Wang et al., 2011; Khodaverdi et al., 2012; Zheng et al. 2013), porém a temperatura é um dos fatores que afeta o processo de adsorção (Site, 2001), assim isotermas de adsorção determinadas em temperaturas diferentes de $50^{\circ} \mathrm{C}$ não são adequadas para representar a hidrólise enzimática da celulose.

Nesse trabalho para que as isotermas de adsorção fossem feitas na temperatura ótima da hidrólise enzimática da celulose $\left(50^{\circ} \mathrm{C}\right)$ sem que houvesse reação e, portanto mudanças nas características estruturais das biomassas durante a determinação das isotermas foi adicionada glicose como inibidor no meio reacional de forma que a relação glicose/celulase fosse fixada em 100:1, pois segundo Maurer et al. (2012) esta é a menor concentração de glicose na qual não há atividade enzimática.

A capacidade de adsorção da celulase em amostras de BH com diferentes tempos de hidrólise foi determinada por meio de isotermas de adsorção apresentadas na Figura 1. A isoterma de Langmuir tem sido amplamente usada para descrever a adsorção de celulases (Kadam et al, 2004; Kumar e Wyman, 2009; Qi et al. 2011; Zheng et al. 2013) pois ela fornece um bom ajuste aos dados experimentais na maioria dos casos, e representa um modelo mecanístico simples que pode ser usado para comparar propriedades cinéticas de vários sistemas celulose-celulase (Zhang e Lynd, 2004).

A isoterma de Langmuir é dada pela equação (1)

$$
E_{a d}=\frac{E_{\max } K_{p} E_{f}}{1+K_{p} E_{f}}(1)
$$

Onde, $\mathrm{E}_{\mathrm{ad}}$ é a enzima adsorvida (mg/g de substrato); $\mathrm{E}_{\max }$ é a adsorção máxima de enzima por $\mathrm{g}$ de substrato ( $\mathrm{mg} / \mathrm{g}$ substrato); $\mathrm{E}_{\mathrm{f}}$ é a concentração de enzima livre ( $\mathrm{mg}$ de enzima/mL) e $\mathrm{K}_{\mathrm{p}}$ é a constante de equilibrio da adsorção ( $\mathrm{mL} / \mathrm{mg}$ de enzima).

Os parâmetros do modelo de Langmuir foram determinados pelo ajuste dos dados experimentais de adsorção da celulase com a Equação (1) por meio do software OriginPro 8.0 (OriginLab,Northampton, MA, USA). 

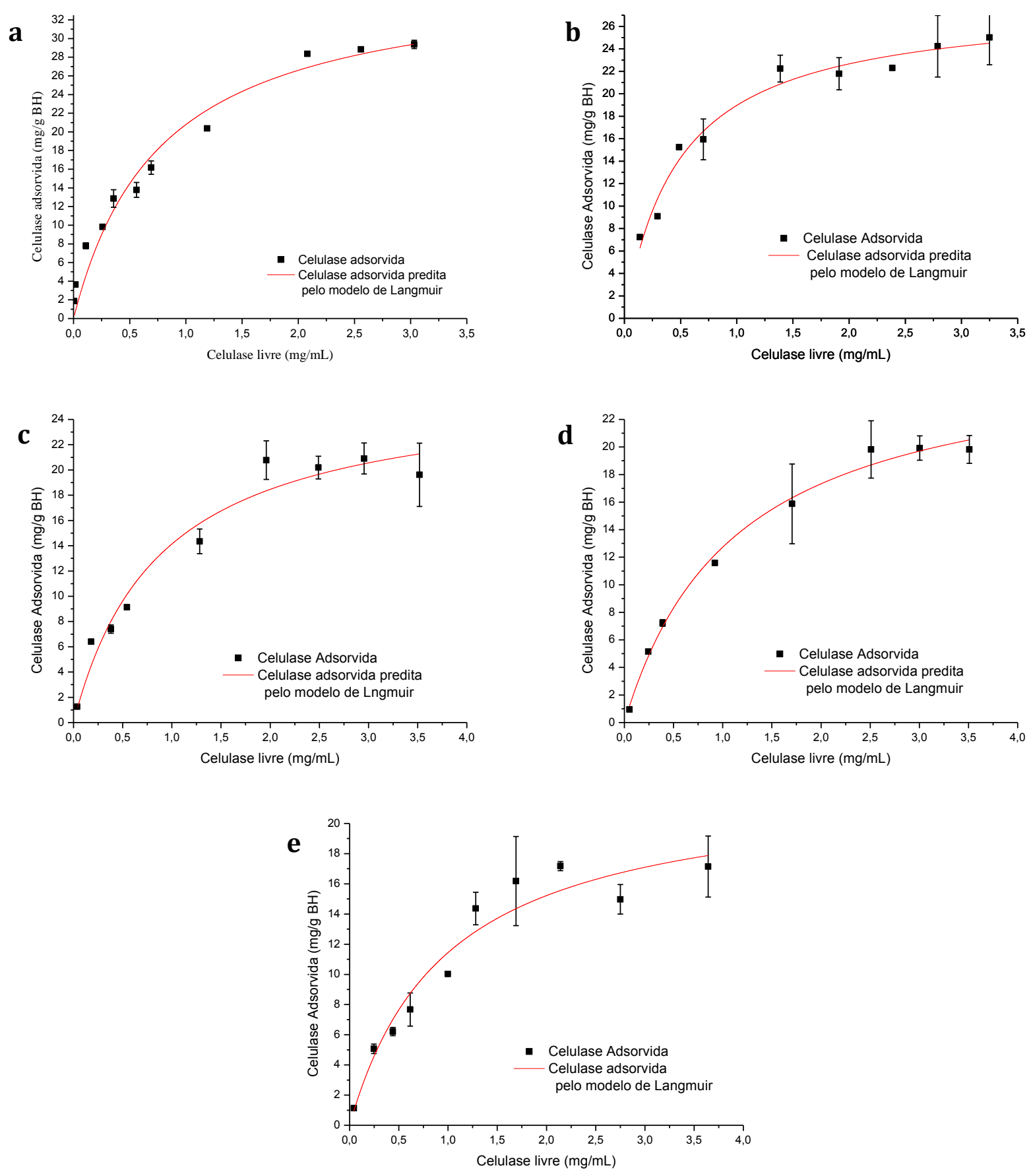

Figura 1 - Isoterma de adsorção da celulase em bagaço de cana pré-tratado em diferentes tempos de hidrólise: a) $\mathrm{t}=0 \mathrm{~h}$; b) $\mathrm{t}=1 \mathrm{~h}$; c) $\mathrm{t}=6 \mathrm{~h}$; d) $\mathrm{t}=12 \mathrm{~h}$; e) $\mathrm{t}=18 \mathrm{~h}$. 


\section{9 a 22 de outubro de 2014 \\ Florianópolis/SC}

Uma vez que o coquetel comercial Celluclast 1,5 L a partir de Trichoderma reesei é um complexo multi-enzimático, a quantificação da adsorção com base no método de Bradford pode também incluir o efeito de outras proteínas presentes no coquetel enzimático. No entanto, conforme apresentado na Figura 1, os dados de adsorção da celulase nas amostras de BH com diferentes tempos de hidrólise foram bem descritos pelo modelo de adsorção de Langmuir. Os parâmetros de Langmuir, $\mathrm{E}_{\max }$ e $\mathrm{K}_{\mathrm{p}}$, para os sistemas estudados encontram-se na Tabela 1

Tabela 1 - Parâmetros de Langmuir para a adsorção da celulase em bagaço de cana pré-tratado

\begin{tabular}{cccc}
\hline Tempo de hidrólise $(\mathrm{h})$ & Emax $(\mathrm{mg}$ celulase/g BH) & $\mathrm{Kp}(\mathrm{mL} / \mathrm{mg}$ celulase $)$ & $\mathrm{R}^{2}$ \\
\hline 0 & $36,933 \pm 2,738$ & $1,286 \pm 0,258$ & 0,963 \\
1 & $28,161 \pm 1,101$ & $2,063 \pm 0,293$ & 0,970 \\
6 & $26,605 \pm 2,215$ & $1,134 \pm 0,284$ & 0,959 \\
12 & $27,13 \pm 1,244$ & $0,884 \pm 0,115$ & 0,992 \\
18 & $22,705 \pm 2,298$ & $1,017 \pm 0,271$ & 0,94 \\
\hline
\end{tabular}

Na Figura 2 foram plotados os parâmetros do modelo de Langmuir ( $E_{\max }$ e $K_{p}$ ) em função do tempo de hidrólise. Durante a hidrólise observa-se que a adsorção máxima da enzima pelo substrato diminui à medida que a reação se segue conforme apresentado na Figura 2a. A maior redução na adsorção máxima da celulase no $\mathrm{BH}$ se dá após a primeira hora de hidrólise onde o valor de $\mathrm{E}_{\max }$ passa de aproximadamente $37 \mathrm{mg}$ celulase/g BH para 28,16 mg celulase/g BH. De 1 à 12 horas de hidrólise o valor de $\mathrm{E}_{\max }$ permanece praticamente constante e diminui para 22,7 mg celulase/g $\mathrm{BH}$ após 18 horas.

Muitos modelos matemáticos de hidrólise enzimática de substratos celulósicos e lignocelulósicos descrevem a etapa de adsorção por meio de isotermas como as de Langmuir e utilizam as mesmas isotermas em todos os momentos da reação (Kadam et al, 2004; Khodaverdi et al., 2012). Esta abordagem assume que as características da adsorção do sistema substrato-enzima não se alteram durante o tempo de hidrólise. A variação nos valores de $\mathrm{E}_{\max }$ e $\mathrm{K}_{\mathrm{p}}$ durante a hidrólise conforme mostra a Figura 2 apontam que a aplicação do modelo de Langmuir com parâmetros fixos na modelagem da hidrólise enzimática não é capaz de descrever com precisão o fenômeno de adsorção da celulase no BH. Diante disso o modelo de Langmuir poderia ser empregado na modelagem desde que $\mathrm{E}_{\max }$ e $\mathrm{K}_{\mathrm{p}}$ fossem correlacionados com uma variável de estado no processo, como o tempo de reação. Resultados semelhantes foram encontrados no trabalho de HONG et al. (2007) com Avicel, onde estes mostraram que a máxima quantidade de enzima adsorvida ( $\mathrm{E}_{\max }$ na isoterma de Langmuir) diminui com a conversão. A diminuição da capacidade máxima de adsorção da enzima pelo substrato ao longo da reação pode estar relacionada às mudanças nas características do BH onde esperasse que durante a hidrólise, a celulose seja degradada por ação enzimática e que tenhamos um substrato cada vez mais rico em lignina. 
a

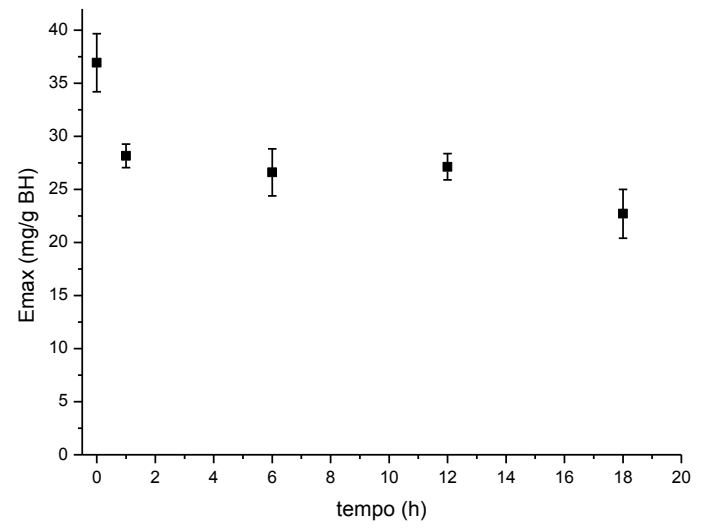

b

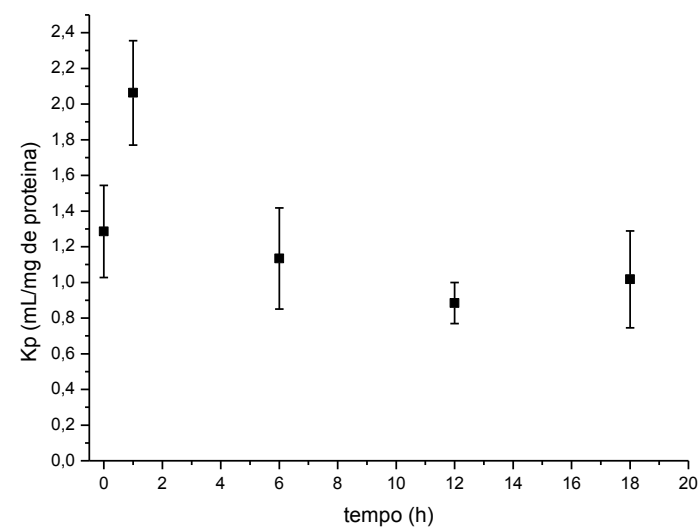

Figura 2 - Variação dos parâmetros da isoterma de adsorção de Langmuir em função do tempo de hidrólise: a) $\mathrm{E}_{\max }$; b) $\mathrm{K}_{\mathrm{p}}$.

\section{CONCLUSÕES}

O modelo de Langmuir utilizado para descrever as isotermas de adsorção foi capaz de representar bem os dados experimentais obtidos para o sistema celulose-celulase. $\mathrm{O}$ estudo da adsorção da celulase em amostras de BH coletadas em diferentes tempos de hidrólise mostrou que a adsorção máxima da enzima no substrato diminui à medida que a reação se segue. A variação dos parâmetros $\mathrm{E}_{\max }$ e $\mathrm{K}_{\mathrm{p}}$ com o tempo de hidrólise mostra que a aplicação do modelo de Langmuir com parâmetros fixos não é capaz de descrever a adsorção no processo de hidrólise enzimática de BH. Os resultados apresentados neste trabalho ressaltam a importância de validar os modelos com uma quantidade de celulase adsorvida medida durante a hidrólise, pois as características da adsorção podem depender do tipo de substrato utilizado e como foi mostrado, os parâmetros da isoterma podem mudar com a conversão.

\section{REFERÊNCIAS}

ADNEY, B e BAKER, J. Chemical analysis and testing task-laboratory analytical procedure. LAP006. National Renewable Energy Laboratory, Golden, CO, USA, 1996.

BÖRJESSON, J. B; PETERSON, R; TJERNELD, F. Enhanced enzymatic conversion of softwood lignocelluloses by poly(ethylene glycol) addition. Enzyme Microb. Tech, v. 40, p. 754-762, 2007.

BRADFORD, M. M. A rapid sensitive method for a quantitation of microgram quantities of protein utilizing the principle of protein-dye binding. Anal Biochem, v. 72, p. 248-254, 1976.

GHOSE, T, K. Measurement of cellulase activities. Pure and Appl. Chem, v.59, p. 257-268, 1987.

KADAM, K. L.; RYDHOLM, E. C; MCMILLAN, J. D. Development and validation of a kinetic model for enzymatic saccharification of lignocellulosic biomass. Biotechnol. Progr, v. 20, p. 698705, 2004. 
KHODAVERDI, M.; JEIHANIPOUR, A.; KARIMI, K; TAHERZADEH, M. J. Kinetic modeling of rapid enzymatic hydrolysis of crystalline cellulose after pretreatment by NMMO. J. Ind. Microbiol. Biot, v. 39, p. 429-438, 2012.

KUMAR, R. e WYMAN, C. E. Cellulase Adsorption and Relationship to Features of Corn Stover Solids Produced by Leading Pretreatments. Biotechnol. Bioeng, v. 103, nº. 2, p. 252-267, 2009.

MAURER, S. A.; BEDBROOK, C. N.; RADKE, C. J. Cellulase Adsorption and Reactivity on a Cellulose Surface from Flow Ellipsometry. Ind. Eng. Chem. Res, v. 51, p. 11389-11400, 2012.

LEVINE, S. E; FOX, J. M; BLANCH, H. W; CLARK, D. S. A Mechanistic Model of the Enzymatic Hydrolysis of Cellulose. Biotechnol. Bioeng, v. 107, nº 1, p.37-51, 2010.

PRIBOWO, A.; ARANTES, V.; SADDLER, J. N. The adsorption and enzyme activity profiles of specific Trichoderma reesei cellulase/xylanase components when hydrolyzing steam pretreated corn stover. Enzyme Microb. Tech, vol. 50, p.195-203, 2012.

QI, B.; CHEN, X.; SU Y. e WAN, Y. Enzyme adsorption and recycling during hydrolysis of wheat straw lignocellulose. Bioresource Technol, v. 102, p. 2881-2889, 2011.

SIPOS, B; DIENES, D; SCHLEICHER, Á; PERAZZINI, R; CRESTINI, C; SIIKA-AHO, M. Hydrolysis efficiency and enzyme adsorption on steam-pretreated spruce in the presence of poly(ethylene glycol). Enzyme Microb. Technol, v.3, p. 84-90, 2010.

SITE, A. D. Factors Affecting Sorption of Organic Compounds in Natural Sorbent/Water Systems and Sorption Coefficients for Selected Pollutants. A Review. J. Phys. Chem. Ref. Data, v. 30, n 1 , p. 187-440, 2001.

TU, M. B; CHANDRA, R. P; SADDLER, J. N. Evaluating the distribution of cellulases and the recycling of free cellulases during the hydrolysis of lignocellulosic substrates. Biotechnol. Prog, v. 2, p.398-406, 2007.

XUE, Y; JAMEEL, H; PHILLIPS, R; CHANG, HOU-MIN. Split addition of enzymes in enzymatic hydrolysis at high solids concentration to increase sugar concentration for bioethanol production. $J$. Ind. Eng. Chem, v. 18, p. 707-714, 2012.

WANG, W.; KANG, L.; WEI, H, et al. Study on the Decreased Sugar Yield in EnzymaticmHydrolysis of Cellulosic Substrate at High Solid Loading. Appl. Biochem. Biotechnol, vol. 164, p.1139-1149, 2011.

WOOD, T, M e BHAT, K, M. Methods for measuring cellulase activities, in: Methods in Enzymology, ed by Wood WA and Kellog ST, Academic Press, San Diego, CA, v. 160, p. 81-112, 1988.

ZHANG, Y. H. P. e LYND, L. R. Toward an aggregated understanding of enzymatic hydrolysis of cellulose: noncomplexed cellulase systems. Biotechnol. Bioeng, v.88, p.797-824, 2004.

ZHENG, Y.; ZHANG, S.; MIAOA, S.; SU, Z. e WANG, P. Temperature sensitivity of cellulase adsorption on lignin and its impact on enzymatic hydrolysis of lignocellulosic biomass. J. Biotechnol, v. 166, p. 135-143, 2013. 